\title{
Effect of exhaust gas recirculation composition on soot in ECN spray A conditions
}

\author{
Chetankumar Patel, Camille Hespel*, Tung Lam Nguyen, Fabrice Foucher, and Christine Mounaïm-Rousselle
}

Université d’Orléans, INSA CVL, PRISME, EA 4229, 45072 Orléans, France

Received: 25 November 2019 / Accepted: 8 April 2020

\begin{abstract}
Due to its strong impact on health, particulate matter is increasingly regulated by government emission standards for vehicles. As one of the sources of particulate matter is the soot produced by internal combustion engines, it remains a challenge to improve advanced combustion modes to reduce it. There is still, however, some lack of understanding about the formation and oxidation processes of soot, especially in "realistic" conditions, such as for example at high temperature and pressure conditions with or without the presence of exhaust gases. The objective of this study is to investigate soot formation in the case of $n$-Dodecane spray flames at conventional Diesel engine conditions generated in the New One Shot Engine by using diffused back-illumination extinction with different $\mathrm{CO}_{2}$ and water vapour contents. It was found that $\mathrm{CO}_{2}$ addition reduces the soot mass fraction if its volumetric concentration in ambient mixtures is at least $4.5 \%$ while $1 \%$ of water is sufficient to significantly reduce the soot mass fraction. The impact of the ambient mixture obtained in ECN spray A pre-burn vessels was also investigated to assess the accuracy against soot measurements available in the literature.
\end{abstract}

\section{Introduction}

Human exposure to soot is responsible for cancer, cardiovascular diseases and respiratory diseases [1]. Soot is an amorphous carbon substance, generally produced during combustion processes. In the case of conventional Diesel combustion, the formation of soot is due to the reduced amount of air available to burn the fuel completely at high temperature and pressure conditions during fuel spray combustion, especially during the diffusion phase [2]. Soot formation is also affected by the presence of other ambient gases such as $\mathrm{CO}_{2}$ or $\mathrm{H}_{2} \mathrm{O}[3,4]$. These gases induce (i) a reduction in interparticle interaction caused by dilution (ii) a change in temperature and heat capacity of the flame caused by thermal effects, and (iii) chemical reactions that either oxidize soot or react with gaseous precursors. As, in modern internal combustion engines, one way to strongly reduce $\mathrm{NO}_{\mathrm{X}}$ is the recirculation of exhaust gas, the presence of $\mathrm{CO}_{2}$ or $\mathrm{H}_{2} \mathrm{O}$ in the combustion chamber is now usual and can impact soot formation. Several numerical and experimental studies about their effects on ethylene (both premixed and diffusion flames) [5-8] concluded that they have an effect on soot reduction, due especially to chemical effects.

Measuring the volume fraction of soot requires the use of optical diagnostics with optimised signal processing.

\footnotetext{
* Corresponding author: camille.hespel@univ-orleans.fr
}

In the context of the Engine Combustion Network [9], it is mainly measured by means of two optical techniques: light based extinction techniques usually called Diffused Back-Illumination (DBI) and Laser-Induced Incandescence (LII) $[10,11]$. The first method is based on the attenuation of light through the soot cloud due to elastic scattering and to absorption by the soot particles. However, in the case of Spray A conditions, i.e. $900 \mathrm{~K}$ and 60 bar as ambient thermodynamic initial conditions, the beam steering is so strong that it becomes difficult to distinguish absorptionor scattering-induced attenuation [12]. Therefore, Ghandhi and Heim [13] worked on the quality of the collimated light needed for DBI and its transmission within the region of interest. In their study, the collimated light of an automotive headlamp was passed through a pinhole and was collected by a Fresnel lens before being transferred to an engineered diffuser to direct it towards the region. A high intensity pulsating LED with $100 \mathrm{~W}$ peak optical power to be used as source for the soot measurement in high pressure-high temperature spray flames was developed recently $[12,14]$. This modified technique is considered as the ECN reference. The data obtained in the Constant volume Preburn Vessel (CPV) were compared with simulation results obtained from different soot models coupled with a large-eddy simulation for $n$-Dodecane combustion $[10,15-17]$ or a $k-\varepsilon$ turbulence model $[18,19]$. The simulations were validated with $15 \%$ of oxygen and various combustion products. To complete the available database 
and to improve modelling concepts, a parametric study on the effects of EGR composition on soot formation for ECN spray A is needed.

In the present study, the New One Shot Engine (NOSE) was used as experimental set-up since the initial conditions required for ECN-spray A are attainable and the ambient mixture composition can be adjusted as desired [20]. The experiments were conducted for Spray A conditions, i.e. $900 \mathrm{~K}$ and $22.8 \mathrm{~kg} / \mathrm{m}^{3}$ with an oxygen concentration of $15 \%$ but with a variation of Nitrogen $\left(\mathrm{N}_{2}\right)$ content with the addition of $\mathrm{CO}_{2}(0-7 \%$ vol $)$ and $\mathrm{H}_{2} \mathrm{O}(0-5 \%$ vol $)$. Moreover, to evaluate the robustness of previous results obtained in other vessels (such as constant pressure flow or constant pre-burn), the impact of ambient compositions similar to those in a CPV as in [9], i.e. $6.22 \% \mathrm{CO}_{2}$ and $3.62 \% \mathrm{H}_{2} \mathrm{O}$, on soot production was also explored.

The next Section 2 discusses the experimental setup and conditions, and is followed by Sections $3-5$.

\section{Experimental setup and conditions}

\subsection{Experimental facility}

The main specifications of NOSE, a one-shot rapid compression machine, and the Spray A - ECN conditions, i.e. $900 \mathrm{~K}, 22.8 \mathrm{~kg} / \mathrm{m}^{3}$, are summarized in Table 1 and fully described in [21]. The $n$-Dodecane fuel was injected through a BOSCH CR2.16 single hole injector at the injection pressure of $150 \mathrm{MPa}$ in the optical chamber filled with a mixture of ambient gases at a constant $\mathrm{O}_{2}$ percentage of $15 \%$ vol (Tab. 2).

\subsection{Ambient gas composition matrix}

Table 2 shows the different compositions of ambient gases selected with a constant oxygen concentration (15\% vol) and the adjustment of $\mathrm{N}_{2}$, alone, according to the addition of $\mathrm{CO}_{2}$ and $\mathrm{H}_{2} \mathrm{O}$. Moreover, to perform tests at a constant ambient gas density inside the chamber the back pressure $\left(P_{\text {back }}\right)$ and the temperature at the injection timing were adjusted. The theoretical adiabatic temperature of the air/fuel mixture for the global equivalence ratio (0.0313) as a function of the ambient gas composition is also indicated.

\subsection{Optical techniques}

Two optical measurements were simultaneously used. First, the $\mathrm{OH}^{*}$ chemiluminescence imaging technique was set up to obtain the Lift-Off Length (LOL) of the flame by using an intensified CMOS camera (Photron - APX-I2) with a UV lens $60 \mathrm{~mm} \mathrm{f} / 3.5$ and a BP filter centered at $310 \mathrm{~nm}$ with FWHM at $10 \mathrm{~nm}$. The frame rate was kept at $2 \mathrm{kHz}$. During the steady phase of combustion (1800$3000 \mu$ s after SOE), three images were analysed following the post-processing recommended by [22].

Second, the measurement of soot was done by DBI, based on the transmission of an initial light with $I_{0}$ as intensity. When this light passes through the sooting flame, a certain amount of the light is absorbed and scattered by
Table 1. Main specifications of new one shot engine for spray A conditions.

\begin{tabular}{lc}
\hline Specifications & Value \\
\hline Volume of the chamber & $\sim 0.24 \mathrm{l}$ \\
Injector tip protrusion & $6 \mathrm{~mm}$ \\
Wall temperature & $373 \mathrm{~K}$ \\
Fuel & $n$-Dodecane \\
Injection pressure & $150 \mathrm{MPa}$ \\
Orifice diameter & $89.7 \mu \mathrm{m}, K_{\mathrm{s}}=1.5, \mathrm{Cd}=0.96$ \\
Ambient temperature & $900 \mathrm{~K}$ \\
Ambient density & $22.8 \mathrm{~kg} / \mathrm{m}^{3}$ \\
Injection duration & $\sim 3.2 \mathrm{~ms}$ \\
\hline
\end{tabular}

the soot and the remainder is transmitted to the receiver, with an intensity of $I$. Using Beer-Lambert's law, the amount of soot can be deduced with the product of the path length, $L$ and the extinction coefficient, $K[23]$ :

$$
\frac{I}{I_{0}}=e^{-K L}
$$

Figure 1 shows the schematic of the DBI setup around NOSE. The light source was generated by a green LED (CBT-120-GC11-JM200) at $\lambda=532 \mathrm{~nm}$. The illuminating rays of the LED were transferred to a Fresnel lens with an effective diameter of $63.5 \mathrm{~mm}$ and a focal length of $99 \mathrm{~mm}$ through a pinhole to generate parallel light beam. Then these rays were transferred to an engineering diffuser to generate a homogeneous distribution of the light in the region of interest. The images of the transmitted light were captured by a Phantom V16 CMOS camera at the frame rate of $45 \mathrm{kHz}$. An AF Micro-Nikon $50 \mathrm{~mm} \mathrm{f} / 1.8 \mathrm{D}$ lens with two filters, a BP filter centered at $532 \mathrm{~nm}$ with $10 \mathrm{~nm}$ FWHM and a neutral density filter of $75 \%$ were used.

The first challenge when applying the DBI technique is to reduce beam steering by choosing the optimal distance between the different optical elements as presented in Figure 1. As indicated in equation (2), the divergence angle of the diffuser, $\theta$ must be larger than the sum of the maximum anticipated beam steering angle, $\alpha$ with the acceptance angle of the collecting optics, $\omega$, as underlined in [23]. If the divergence angle of the diffuser is not large enough, then there is a possibility that some area of the extinction beam might be moved out of the imaged area. However, the diffuser used in our setup has a $15^{\circ}$ divergence angle $\theta$ and the acceptance angle $\omega$ of our optics is $8.36^{\circ}$, this system therefore ensures a beam steering angle, $\alpha$ of $6.64^{\circ}$ which is large enough to fulfil the first requirement [9]:

$$
\theta \geq \alpha+\omega .
$$

The second criterion is the size of the collimated beam. The beam diameter, $D$ should be higher than the sum of the probe volume, $S$ and the tangential of the addition of the beam steering angle and the acceptance angle across the length $L$, between the probe volume and the CMOS 
Table 2. Test conditions.

\begin{tabular}{lccccccc}
\hline Nomenclature & \multicolumn{3}{c}{$\begin{array}{c}\text { Ambient gas } \\
\text { composition }(\% \text { volume })\end{array}$} & $\begin{array}{c}P_{\text {back }} \text { at injection } \\
\text { timing }(\mathrm{MPa})\end{array}$ & $\begin{array}{c}\mathrm{T} \text { at real injection } \\
\text { timing }[\mathrm{K}] \pm 4 \mathrm{~K}\end{array}$ & $\begin{array}{c}\text { Adiabatic Flame } \\
\text { Temperature }\end{array}$ \\
\cline { 2 - 5 } & $\mathrm{O}_{2}$ & $\mathrm{~N}_{2}$ & $\mathrm{CO}_{2}$ & $\mathrm{H}_{2} \mathrm{O}$ & & 901 & 957 \\
\hline $0 \% \mathrm{CO}_{2} / 0 \% \mathrm{H}_{2} \mathrm{O}$ & 15.00 & 85.00 & $x$ & $x$ & 6.0 & 901 & 957 \\
$2 \% \mathrm{CO}_{2}$ & 15.00 & 83.00 & 2.00 & $x$ & 5.9 & 898 & 954 \\
$4.5 \% \mathrm{CO}_{2}$ & 15.00 & 80.50 & 4.50 & $x$ & 5.8 & 890 & 946 \\
$7 \% \mathrm{CO}_{2}$ & 15.00 & 78.00 & 7.00 & $x$ & 5.7 & 901 & 957 \\
$1 \% \mathrm{H}_{2} \mathrm{O}$ & 15.00 & 84.00 & $x$ & 1.00 & 6.0 & 901 & 957 \\
$2 \% \mathrm{H}_{2} \mathrm{O}$ & 15.00 & 83.00 & $x$ & 2.00 & 6.0 & 900 & 956 \\
$3 \% \mathrm{H}_{2} \mathrm{O}$ & 15.00 & 82.00 & $x$ & 3.00 & 6.0 & 898 & 953 \\
$4 \% \mathrm{H}_{2} \mathrm{O}$ & 15.00 & 81.00 & $x$ & 4.00 & 6.0 & 895 & 950 \\
$5 \% \mathrm{H}_{2} \mathrm{O}$ & 15.00 & 80.00 & $x$ & 5.00 & 6.0 & 889 & 945 \\
$6.22 \% \mathrm{CO}_{2}+3.63 \% \mathrm{H}_{2} \mathrm{O}$ & 15.00 & 75.15 & 6.22 & 3.63 & 5.7 & & \\
\hline
\end{tabular}

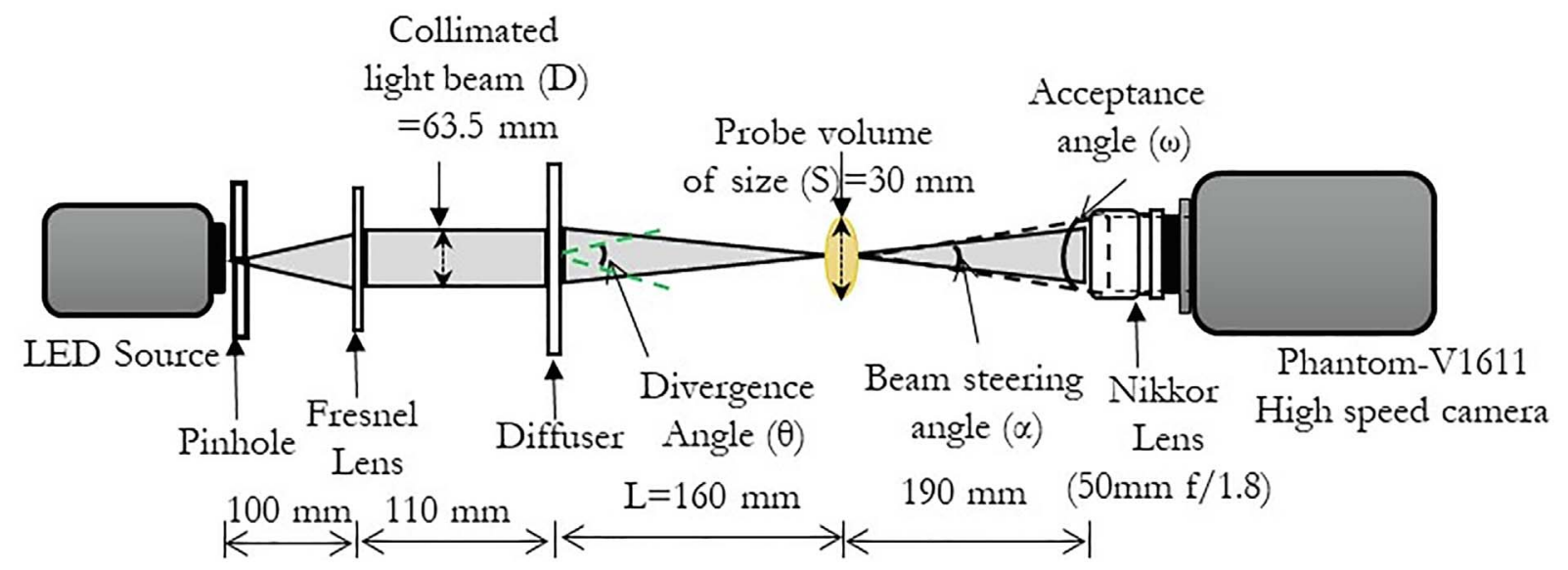

Fig. 1. Detailed optical arrangement at DBI setup.

sensor. If this criterion is not fulfilled, there will be beam steering along the edges of the probe volume,

$$
D \geq S+\tan (\alpha+\omega) \cdot L
$$

This is obtained for the present optical setup for a beam steering angle, $\alpha=2.86^{\circ}$ [12].

Another issue is the effect of the "negative image lag", due to the incomplete reset of the CMOS sensor during the pixel readout. The residual signal with this negative image lag affects the next image and therefore the estimate of KL. However, this effect can be removed by analysing a third image without LED. In our case a comparison of LED off frame with and without LED pulsing showed that the residual negative signal is negligible. The high speed camera acquired the images with and without LED light, a frame rate of $45 \mathrm{kHz}$ with an exposure time of $3 \mu \mathrm{s}$ while the LED frequency was kept at 22500 pulse/sec, as shown in Figure 2. This choice is a good compromise between a good temporal resolution, a high stability of the light-source intensity and very low negative image lag.

\subsection{Image processing}

Figure 3 describes the different steps followed to postprocess the DBI image as recommended in [23] by the ECN. The first image corresponds to when the LED is ON, and consists of the LED signal and the natural luminosity of the soot cloud, $I_{\mathrm{LED}+\mathrm{NL}}$. Complete LED-light extinction is never measured. The second image is obtained for the LED off frame and consists purely of the natural luminosity signal, $I_{\mathrm{NL}}$. Images of the background due to the dark noise were previously recorded and due to the CMOS technology, it was considered as to be zero. The third image represents the light intensity without flame and soot, $I_{0}$ in the probe volume $S$. Soot extinction, KL, for one DBI image, $j$, is obtained thanks to equation (1),

$$
\mathrm{KL}=-\ln \left(\frac{I_{\mathrm{LED}}}{I_{0}}\right)
$$

where $I_{\mathrm{LED}}=I_{\mathrm{LED}+\mathrm{NL}, j}-I_{\mathrm{NL}, j-1}$. 


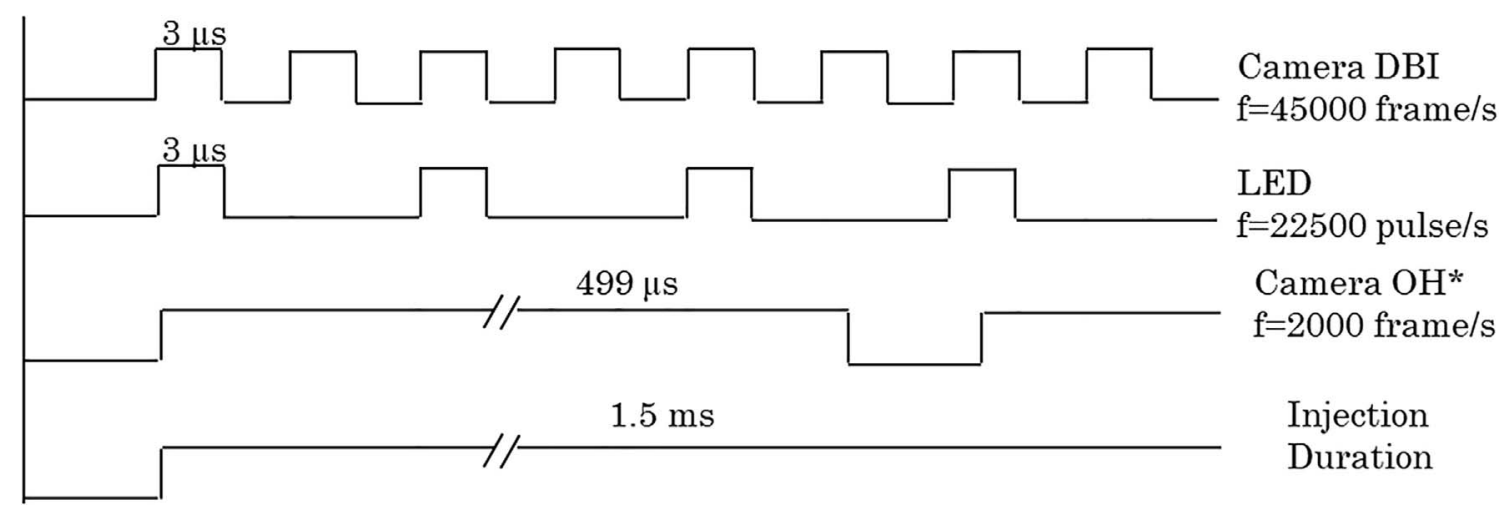

Fig. 2. Signal arrangement for the setup.

LED On

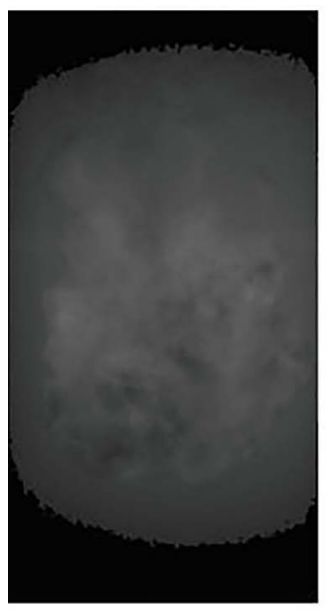

$I_{L E D+N L}$

\section{LED Off}

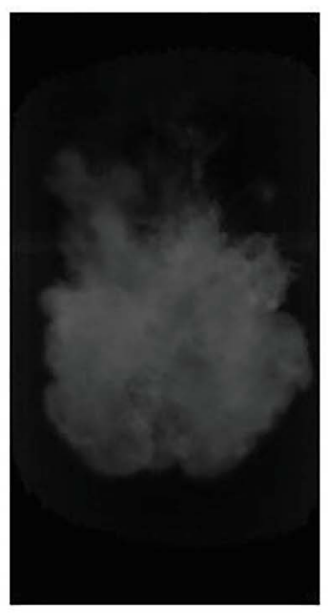

$I_{N L}$

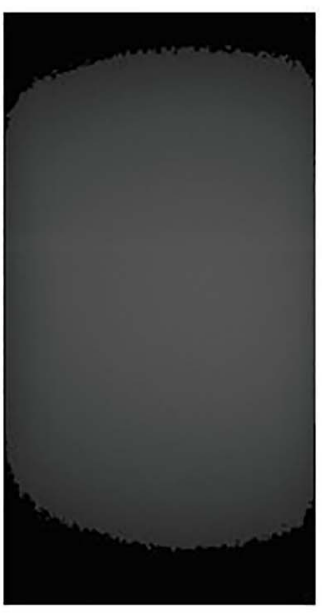

$I_{0}$

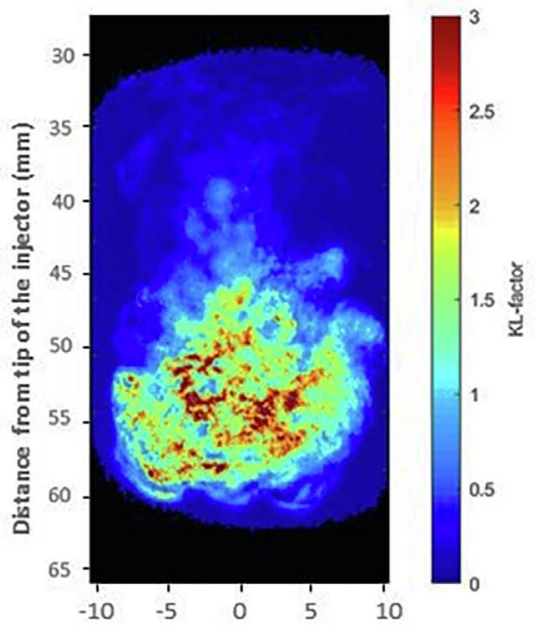

Fig. 3. Steps for the post processing of the KL factor.

The image presented in the right-most panel of Figure 3 corresponds to the processed image: a $2 \mathrm{D}$ distribution of soot extinction, KL.

The soot mass can be estimated by equation (5), with $\rho_{\text {soot }}$, the soot density, considered as $1.8 \mathrm{~g} / \mathrm{cm}^{3}$ as in [24], $k_{e}$, the non-dimensional extinction coefficient, set at 7.46 as in [25] and $\mathrm{d} x, \mathrm{~d} y$ the pixel sizes, here $11.2 \mu \mathrm{m} / \mathrm{pix}$,

$$
m_{\text {soot }}=\frac{\lambda_{\text {LED }} \rho_{\text {soot }}}{k_{e}} \mathrm{~d} x \int_{-R}^{R} \operatorname{KL~d} y .
$$

\section{Results}

This section is divided into three parts. The first part focuses on the comparison between the results obtained in the reference condition, i.e. $15 \% \mathrm{O}_{2}, 85 \% \mathrm{~N}_{2}$ and the ECN pre-burn condition, namely with $\mathrm{CO}_{2}$ and $\mathrm{H}_{2} \mathrm{O}$ residue from the pre-combustion $\left(15 \% \mathrm{O}_{2}, 75.15 \% \mathrm{~N}_{2}, 6.22 \%\right.$ $\mathrm{CO}_{2}$, and $3.63 \% \mathrm{H}_{2} \mathrm{O}$ ). The second and the third parts will cover the effects of $\mathrm{CO}_{2}$ and water vapour addition on the flame soot, respectively.

\subsection{Effect of pre-burn products}

Figure 4 presents an example of the soot extinction images obtained at $15 \% \mathrm{O}_{2}, 75.15 \% \mathrm{~N}_{2}, 6.33 \% \mathrm{CO}_{2}$, and $3.62 \%$ $\mathrm{H}_{2} \mathrm{O}$, representing ECN pre-burn conditions in comparison with those obtained without any exhaust gases i.e. the reference condition of $15 \% \mathrm{O}_{2}$ and $85 \% \mathrm{~N}_{2}$, the reference condition, from $1.022 \mathrm{~ms}$ to $1.689 \mathrm{~ms}$ after the start of injection. For the two cases, the soot area increases with the combustion development. Soot formation starts in the periphery of the jet, due to the higher temperature and comparatively leaner mixture in the surrounding as compared to the central part of the jet [26]. During the flame development, soot volume fraction increases at the core of the jet (images from $1.378 \mathrm{~ms}$ to $1.689 \mathrm{~ms}$ ) and stabilizes at the periphery. According to Cenker et al. [26] the air entrainment increases, soot first starts to oxidize in oxygen-rich high-temperature 

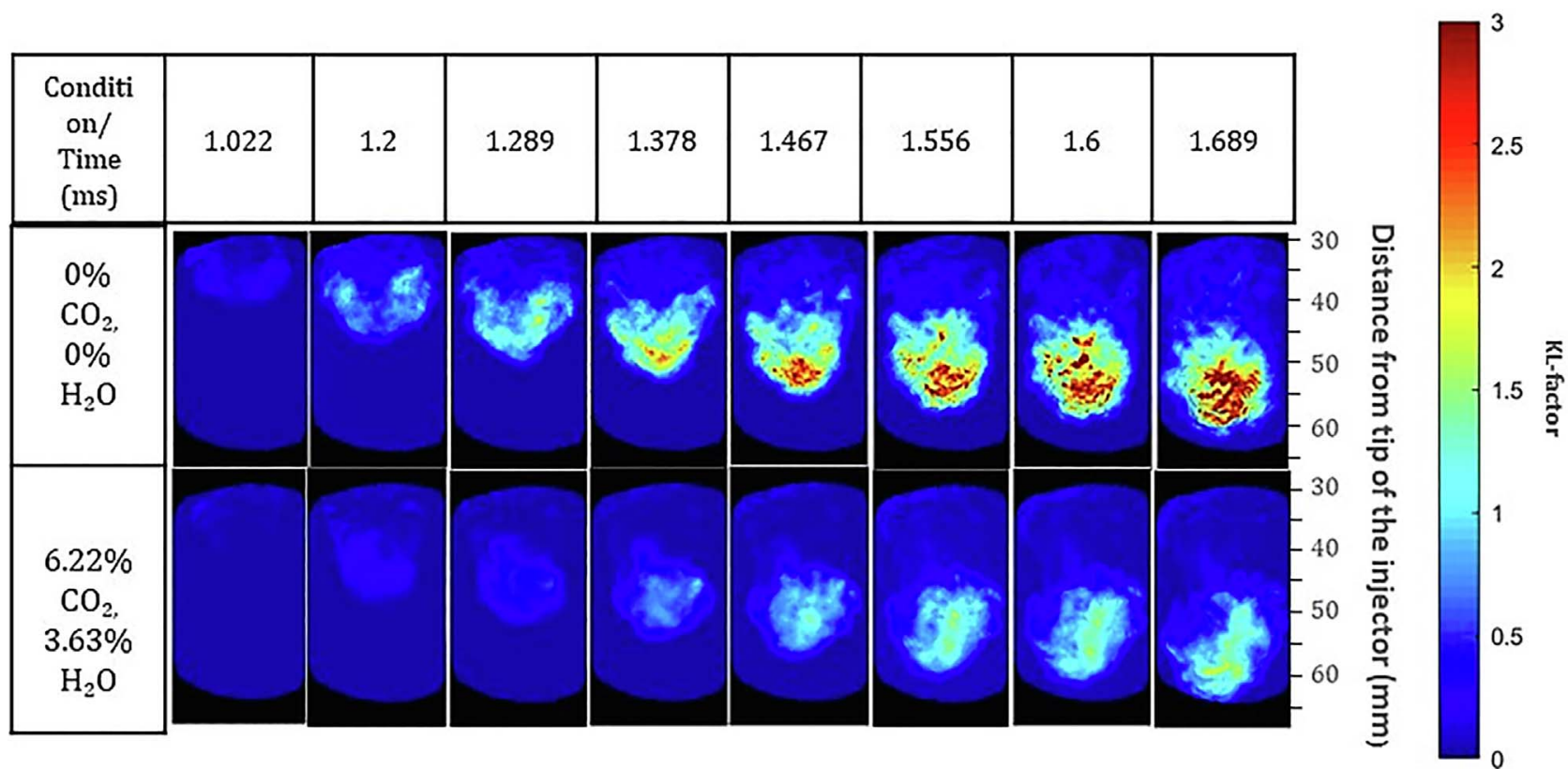

Fig. 4. Example of soot extinction images - comparison with ECN preburn gases composition and no exhaust gases in ambient gases (reference case).

zones such as the boundaries of the jet. The highest level of soot extinction is observed at the head of the front at $1.689 \mathrm{~ms}$. After this event, the head of the soot cloud is outside the observation area but traces of the soot are observed till $\sim 4 \mathrm{~ms}$ for the tail of the flame.

In this example, two trends can be observed: the soot onset time is shifted when pre-burn gases are taken into account in the ambient gases, and the extinction level is decreased by at least half. Ten repetitive tests were conducted to determine an average image. The maximum soot extinction value is 3 for the ECN pre-burn condition, against 4.5 for the reference condition. In Figure 5, the average $\mathrm{KL}$ factor, normalized by the maximum value obtained for the reference case is plotted as a function of the time After the Start of Injection (ASOI).The temporal evolution of KL values follows the same pattern as that presented by Musculus and Pickett [27] or [11, 23]. KL values reach the maximum when the head of the jet passes through the field of view. Once the head of the jet has passed through this position, the tail of the flame appears in the observation window till $\sim 4 \mathrm{~ms}$. In this part, the KL factor decreases by $40 \%$ in the two cases.

Figure $6 \mathrm{a}$ presents the estimate of soot mass $50 \mathrm{~mm}$ from the injector tip for ECN and reference conditions. The soot mass is reduced by $50 \%$ with the presence of $6.22 \% \mathrm{CO}_{2}$ and $3.63 \% \mathrm{H}_{2} \mathrm{O}$ in the ambient gases. Figure $6 \mathrm{~b}$ presents the comparison between the total soot mass for both conditions with the results obtained in [7], named "SNL CVP vessel". The soot mass fraction for the ECN condition with pre-burn constituents in the ambient gases is around half of $51 \mu \mathrm{g}$, obtained in reference conditions. The value of, $25 \mu \mathrm{g}$ is in good agreement with the results obtained in the actual pre-burn vessel [9]. Thanks to this comparison, it is highlighted that this reduction can be mainly attributed to the presence of inert gases, here

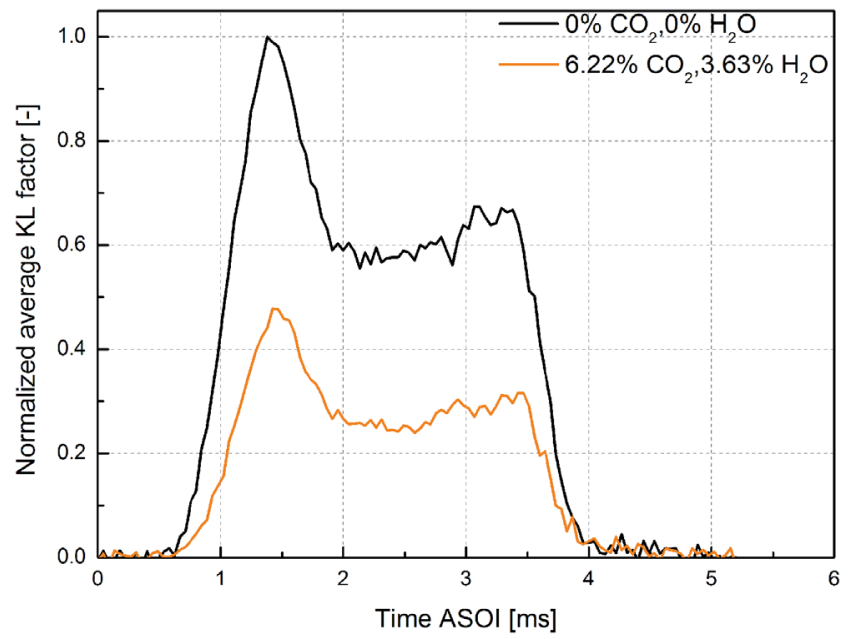

Fig. 5. Normalized average KL factor for ECN condition with pre-burn ambient gases composition and for reference condition, $15 \% \mathrm{O}_{2}$ and $85 \% \mathrm{~N}_{2}$.

a mixture of $\mathrm{CO}_{2}$ and $\mathrm{H}_{2} \mathrm{O}$, certainly due to the chemical reaction supported with dilution and thermal effects as discussed below.

\subsection{Effects of $\mathrm{CO}_{2}$ addition on soot}

The average KL factor, obtained for 10 individual tests, and normalized by the maximum value obtained for the reference condition is presented in Figure 7a for the four amounts of $\mathrm{CO}_{2}$. It can be clearly seen that the soot onset time is shifted. This shows that $2 \% \mathrm{CO}_{2}$ does not affect the soot extinction levels but that a significant decrease is obtained when at least $4.5 \%$ is added. In Figure $7 \mathrm{~b}$, the 
(a)

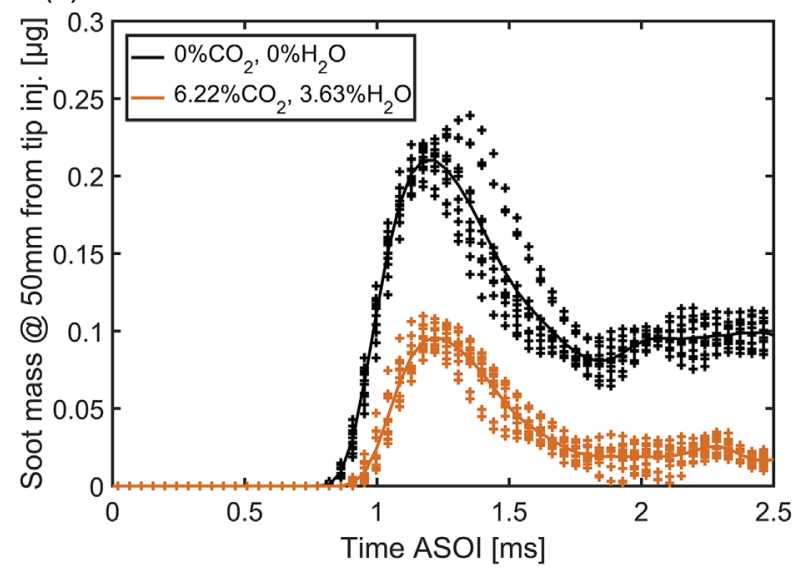

(b)

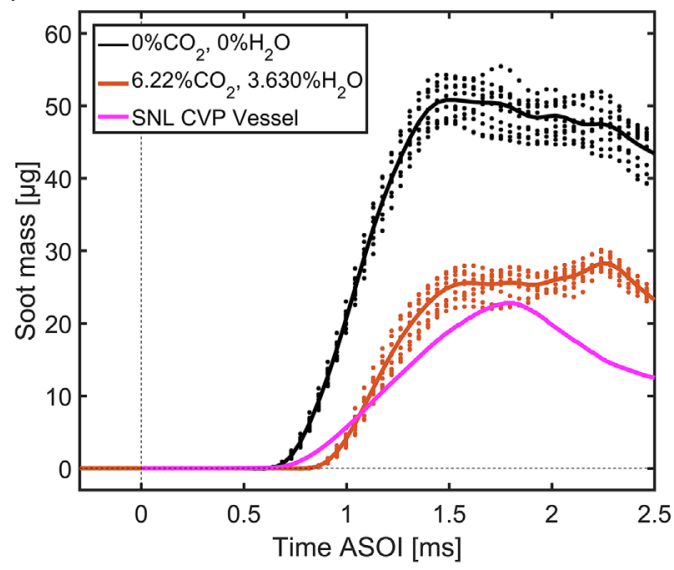

Fig. 6. (a) Soot mass $50 \mathrm{~mm}$ from the injector tip, (b) soot mass comparison with results in pre-burn vessel [9].

(a)

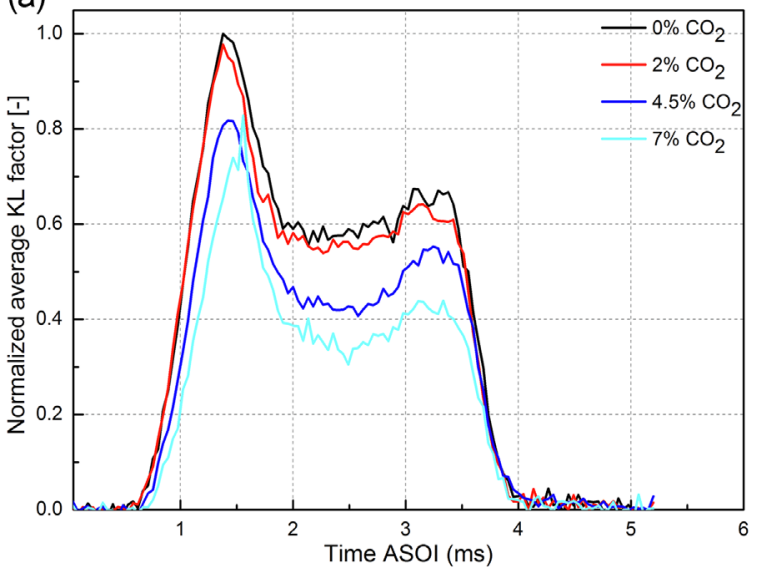

(b)

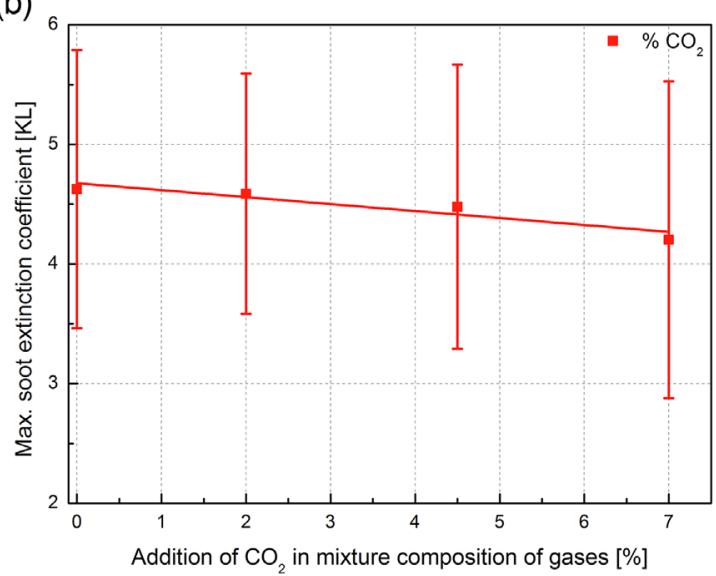

Fig. 7. (a) Normalized average KL factor versus time, (b) maximum of KL factor versus $\mathrm{CO}_{2}$ content.

linear decrease of the maximum KL value is presented as a function of $\mathrm{CO}_{2}$ content. For example, with $4.5 \%$ of $\mathrm{CO}_{2}$ the maximum KL factor is decreased by $5.4 \%$. These trends are also highlighted by the plot of the total soot mass estimate on the field of view (Fig. 8a). The highest quantity of total soot mass is observed for 0 and $2 \% \mathrm{CO}_{2}$ addition with a maximum at $\sim 51 \mu \mathrm{g}$ and $\sim 48 \mu \mathrm{g}$ respectively, while 4.5 and $7 \%$ addition of $\mathrm{CO}_{2}$ decrease this maximum to $\sim 43 \mu \mathrm{g}$ and $\sim 35 \mu \mathrm{g}$. Thus, a simple linear relationship can be suggested as expressed in equation (6) and seen in Figure $8 \mathrm{~b}$ with a $R$-square of 0.97 :

$$
\frac{m_{\text {soot }, \mathrm{CO}_{2} \%}}{m_{\text {soot }, 0 \%}}=1-0.045 \cdot \mathrm{CO}_{2} \% \text {. }
$$

\subsection{Effect of $\mathrm{H}_{2} \mathrm{O}$ addition}

The same trends can be observed with a variation in $\mathrm{H}_{2} \mathrm{O}$ content from $1 \%$ to $5 \%$ : a shift of soot onset time and a reduction in the extinction level. However, as soon as $1 \%$ $\mathrm{H}_{2} \mathrm{O}$ is introduced, a significant effect is observed on the average KL factor, with $15 \%$ of reduction, as can be seen in Figure 9a. This trend is highlighted by the evolution of the maximum KL factor versus the percentage of $\mathrm{H}_{2} \mathrm{O}$, plotted in Figure 9b. A 20\% reduction in this maximum is obtained when $5 \% \mathrm{H}_{2} \mathrm{O}$ is added.

Figure 10 presents the total soot mass (a) and the maximum soot mass reached between $1 \mathrm{~ms}$ and $2 \mathrm{~ms}$ after the start of injection (b) as a function of water vapour content in the ambient mixture. The impact on the soot mass is pronounced, as, the maximum value of total soot mass is reduced to $38 \%$ with $5 \% \mathrm{H}_{2} \mathrm{O}$ compared to the reference case. The following linear relationship $(R$-square $=0.95)$ can be suggested

$$
\frac{m_{\text {soot }, \mathrm{H}_{2} \mathrm{O} \%}}{m_{\text {soot }, 0 \%}}=1-0.066 \cdot \mathrm{H}_{2} \mathrm{O} \% \text {. }
$$

\section{Discussion}

It was clearly observed that $\mathrm{H}_{2} \mathrm{O}$ has a stronger effect on soot reduction than $\mathrm{CO}_{2}$. For example, $2 \%$ of $\mathrm{CO}_{2}$ or 
(a)

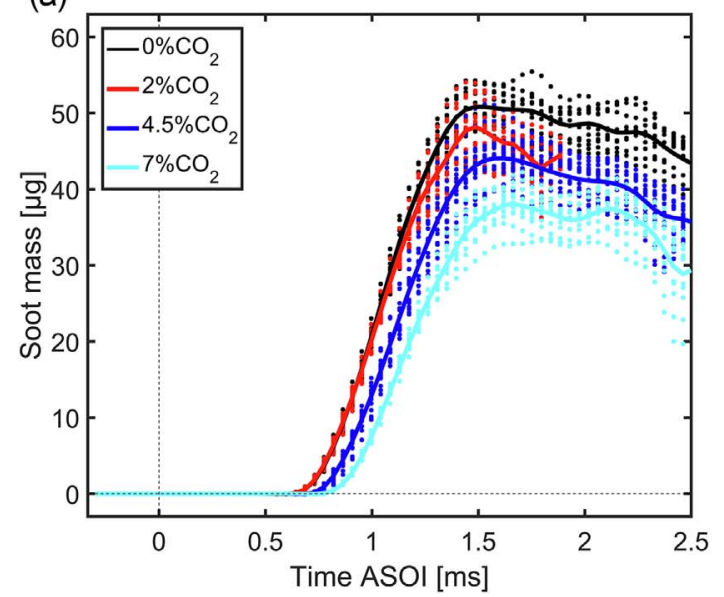

(b)

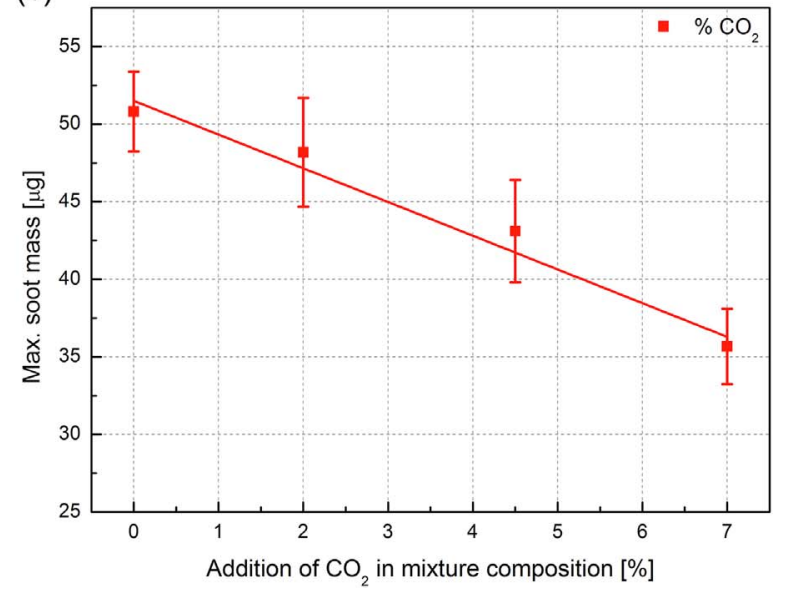

Fig. 8. Comparison of soot mass for different $\mathrm{CO}_{2}$ content in ambient mixture (a) total soot mass, (b) maximum of soot mass between $1 \mathrm{~ms}$ and $2 \mathrm{~ms}$ ASOI.
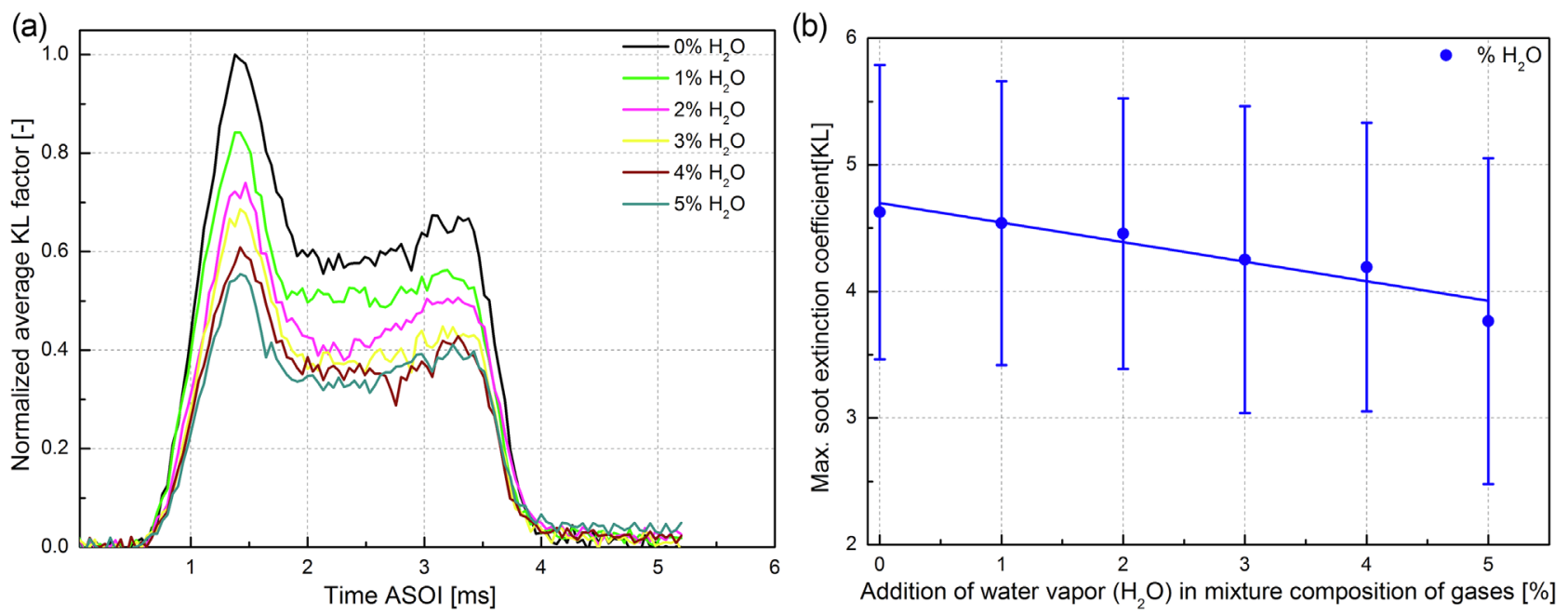

Fig. 9. (a) Normalized average $\mathrm{KL}$ factor as a function of $\mathrm{H}_{2} \mathrm{O}$ content, (b) maximum soot extinction coefficient as a function of $\mathrm{H}_{2} \mathrm{O}$ content.

(a)

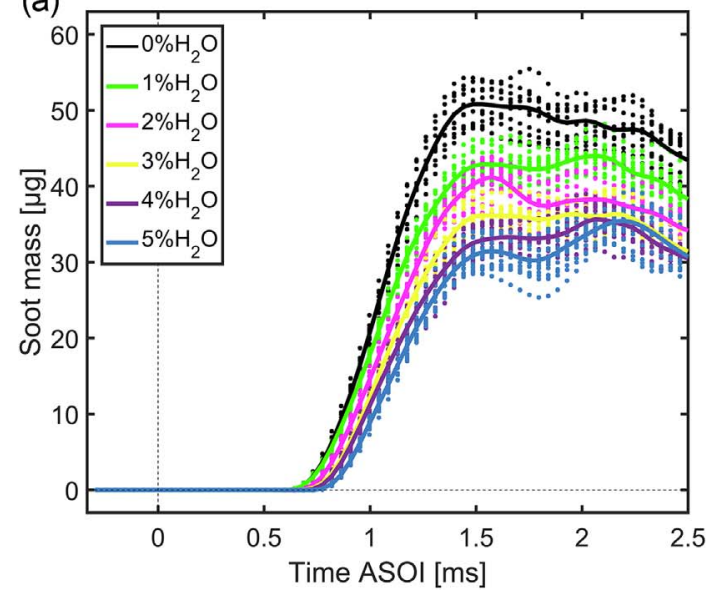

(b)

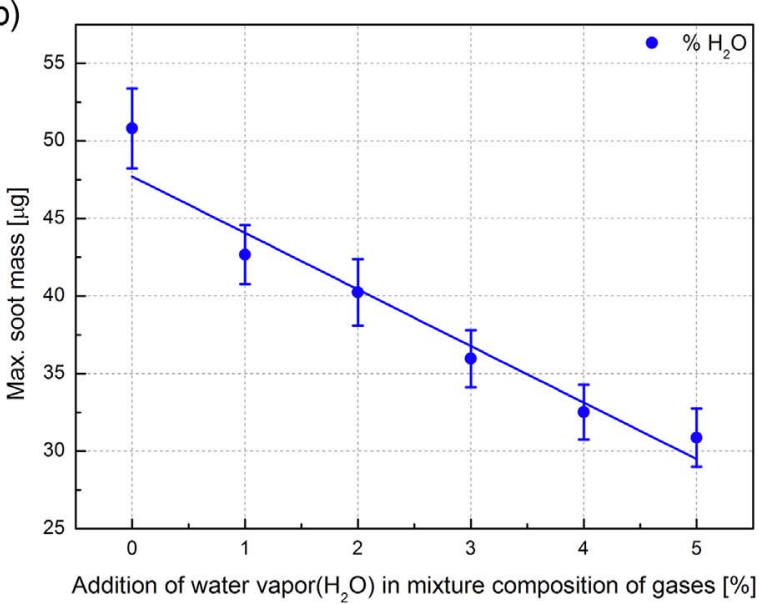

Fig. 10. Comparison of soot mass fraction as a function of $\mathrm{H}_{2} \mathrm{O}$ content in mixture composition (a) total soot mass, (b) maximum soot mass between $1 \mathrm{~ms}$ and $2 \mathrm{~ms}$ ASOI. 
(a)

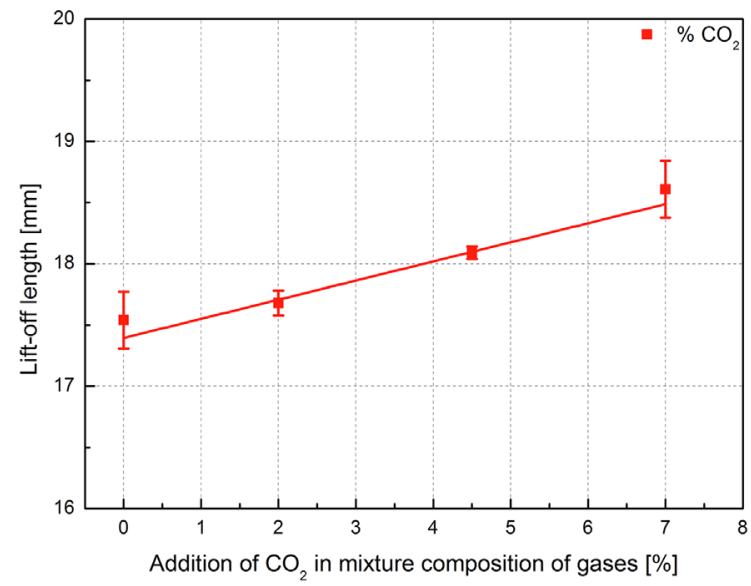

(b)

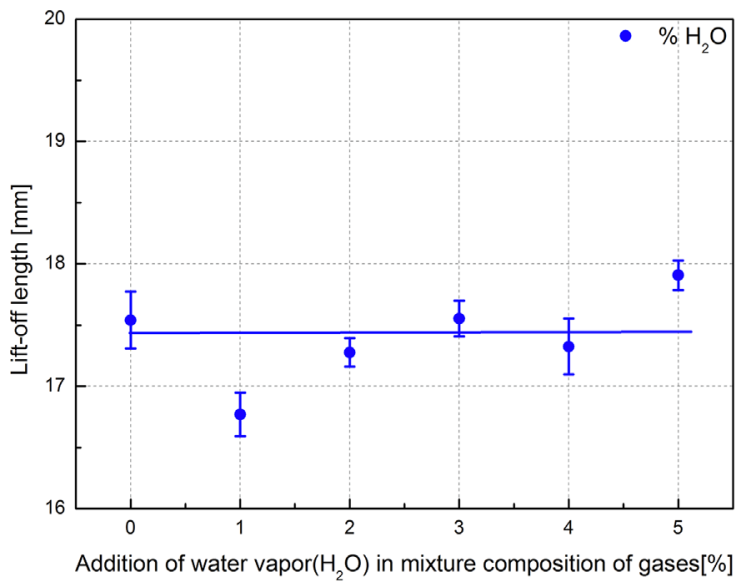

Fig. 11. Lift-off length as a function of the (a) $\mathrm{CO}_{2}$ or (b) $\mathrm{H}_{2} \mathrm{O}$ addition in ambient gases.

of $\mathrm{H}_{2} \mathrm{O}$ resulted in a $5 \%$ and $20 \%$ reduction in the maximum soot value, respectively. Similar results were observed by Zhang et al. [6]. They found a more significant reduction of Polycyclic Aromatic Hydrocarbons (PAH) formation by $\mathrm{H}_{2} \mathrm{O}$ when compared to $\mathrm{CO}_{2}$ for the same blending ratio in laminar premixed $\mathrm{C}_{2} \mathrm{H}_{4} / \mathrm{O}_{2} / \mathrm{Ar}$ flames. The soot onset time is also more delayed with $\mathrm{H}_{2} \mathrm{O}$ compared to $\mathrm{CO}_{2}$.

The reduction in soot with the addition of $\mathrm{CO}_{2}$ or $\mathrm{H}_{2} \mathrm{O}$ in ambient gases can be attributed to different effects. First, due to the thermal capacities of these species in comparison to $\mathrm{N}_{2}$, the flame temperature has to be reduced [28]. It can be noted that $7 \% \mathrm{CO}_{2}$ induced only a $\sim 1.15 \%$ reduction in the adiabatic flame temperature (so from $957 \mathrm{~K}$ to $946 \mathrm{~K}$ ) and $5 \% \mathrm{H}_{2} \mathrm{O}$ induced only a $\sim 0.73 \%$ reduction in the adiabatic flame temperature (from $957 \mathrm{~K}$ to $950 \mathrm{~K}$ ). As the impact on temperature is very small, other effects have to be considered according to [4].

The presence of $\mathrm{CO}_{2}$ or $\mathrm{H}_{2} \mathrm{O}$ in the ambient gases can also affect the location of the flame stabilization. This is highlighted in Figure 11 where an increase in the lift-off length can be noticed in the case of $\mathrm{CO}_{2}$ (Fig. 11a) but not in the case of $\mathrm{H}_{2} \mathrm{O}$ (Fig. 11b) as the variation is on the same order of variability. In fact the LOL depends on the initial ambient temperature [29] and in Table 2, the addition of $\mathrm{CO}_{2}$ induces an initial temperature reduction of $11 \mathrm{~K}$ while only $6 \mathrm{~K}$ with the addition of $\mathrm{H}_{2} \mathrm{O}$. Figure 12 highlights the good correlation between LOL and the scaling law LOL* [29]. The variation in initial ambient temperature could explain the evolution of the LOL with addition of $\mathrm{CO}_{2}$.

The flame with addition of $\mathrm{CO}_{2}$ is stabilized in a leaner area, which could contribute to a soot reduction [29, 30]. However, as the effect of $\mathrm{H}_{2} \mathrm{O}$ is greater than of $\mathrm{CO}_{2}$, the soot reduction has to be mainly attributed according to $[3,5,6,31]$, to the chemical reactions.

In the case of $\mathrm{CO}_{2}$, an interaction with $\mathrm{H}$ radicals such as $\mathrm{CO}_{2}+\mathrm{H} \leftrightarrow \mathrm{OH}+\mathrm{CO}$, increases the amount of hydroxyl radicals, which enhances the oxidation process of the soot precursors. In the case of $\mathrm{H}_{2} \mathrm{O}$, as specified in [5], both

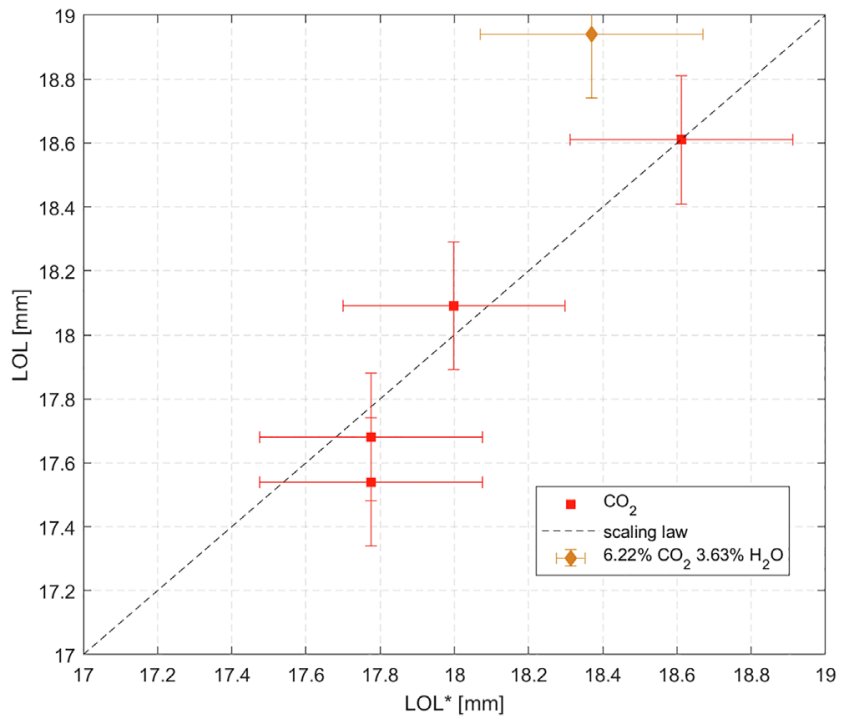

Fig. 12. LOL versus $\mathrm{LOL}^{*}$ with addition of $\mathrm{CO}_{2} \mathrm{LOL}^{*}=$ $\mathrm{LOL}_{\text {ref }}\left(\frac{T_{\text {amb }}}{T_{\text {ref }}}\right)^{-3,74}$ with $\mathrm{LOL}_{\text {ref }}=17,85 \mathrm{~mm}$ and $T_{\text {ref }}=900 \mathrm{~K}$.

the reverse reactions of $\mathrm{H}_{2} \mathrm{O}+\mathrm{H} \leftrightarrow \mathrm{OH}+\mathrm{H}_{2}$ and $\mathrm{H}_{2} \mathrm{O}+$ $\mathrm{O} \leftrightarrow \mathrm{OH}+\mathrm{OH}$ mainly contribute to reducing the formation of soot. According to Teini et al. [3], the addition of $\mathrm{CO}_{2}$ and $\mathrm{H}_{2} \mathrm{O}$ influences the growth of $\mathrm{OH}$ radicals in different areas of the flame. While $\mathrm{CO}_{2}$ may begin to deplete soot mass through $\mathrm{OH}$ radical attacks in the oxidation zone, $\mathrm{H}_{2} \mathrm{O}$, inhibited $\mathrm{PAH}$ molecule growth reactions in fuel rich, soot formation regions. It results in the higher reduction of soot with $\mathrm{H}_{2} \mathrm{O}$ addition as compared to $\mathrm{CO}_{2}$.

\section{Conclusion}

Thanks to the NOSE experimental set-up, the effects of presence of $\mathrm{CO}_{2}$ and $\mathrm{H}_{2} \mathrm{O}$ in ambient mixtures on soot 
formation were evaluated for the first time in the case of dodecane spray combustion. It was clearly observed that $\mathrm{H}_{2} \mathrm{O}$ has a stronger effect on soot reduction than $\mathrm{CO}_{2}$, as previously observed in ethane flames. The soot reduction is certainly due to reactions between $\mathrm{H}$ radicals and $\mathrm{CO}_{2}$ or $\mathrm{H}_{2} \mathrm{O}$ and between $\mathrm{O}$ radical and $\mathrm{H}_{2} \mathrm{O}$. The reactions promote $\mathrm{OH}$ radicals which are reduced by oxidation in $\mathrm{PAH}$. By combining $\mathrm{CO}_{2}$ and $\mathrm{H}_{2} \mathrm{O}$ in the ambient mixture as in real ECN pre-burn conditions, a reduction of $50 \%$ in comparison to the reference condition $\left(15 \% \mathrm{O}_{2}+85 \% \mathrm{~N}_{2}\right)$ is estimated and is in very good agreement by real measurements in a pre-burn vessel. This confirms that the presence of these species has to be considered in any simulations of results for ECN pre-burn vessels in order to increase the model prediction accuracy.

Acknowledgments. The authors acknowledge the National Research Agency (contract ANR-14-CE22-0015-01) for financial support to the ECN-France project and Region Centre Val de Loire (CPER 2007-2013 Energies du Futur) and FEDER for financial support to build the NOSE set-up. The authors thank H. Ajrouche, O. Nilaphai, Y. Haidous, and B. Moreau for helping with the experiments. The authors greatly acknowledge the valuable discussions with G. Bruneaux.

\section{References}

1 Durant J.L., Busby W.F., Lafleur A.L., Penman B.W., Crespi C.L. (1996) Human cell mutagenicity of oxygenated, nitrated and unsubstituted polycyclic aromatic hydrocarbons associated with urban aerosols, Mutat. Res. Toxicol. 371, 123-157. doi: 10.1016/S0165-1218(96)90103-2.

2 Kumfer B.M., Skeen S.A., Axelbaum R.L. (2008) Soot inception limits in laminar diffusion flames with application to oxy-fuel combustion, Combust. Flame 154, 546-556. doi: 10.1016/J.COMBUSTFLAME.2008.03.008.

3 Teini P.D., Karwat D.M.A., Atreya A. (2012) The effect of $\mathrm{CO}_{2} / \mathrm{H}_{2} \mathrm{O}$ on the formation of soot particles in the homogeneous environment of a rapid compression facility, Combust. Flame 159, 1090-1099. doi: 10.1016/j.combustflame. 2011.10.002.

4 Du D.X., Axelbaum R.L., Law C.K. (1991) The influence of carbon dioxide and oxygen as additives on soot formation in diffusion flames, Symp. Combust. 23, 1501-1507. doi: 10.1016/S0082-0784(06)80419-4.

5 Liu F., Consalvi J.L., Fuentes A. (2014) Effects of water vapor addition to the air stream on soot formation and flame properties in a laminar coflow ethylene/air diffusion flame, Combust. Flame 161, 1724-1734. doi: 10.1016/j.combustflame. 2013.12.017.

6 Zhang Y., Wang L., Liu P., Guan B., Ni H., Huang Z., Lin H. (2018) Experimental and kinetic study of the effects of $\mathrm{CO}_{2}$ and $\mathrm{H}_{2} \mathrm{O}$ addition on $\mathrm{PAH}$ formation in laminar premixed $\mathrm{C}_{2} \mathrm{H}_{4} / \mathrm{O}_{2} /$ Ar flames, Combust. Flame 192, 439-452. doi: 10.1016/j.combustflame.2018.01.050.

7 Hoerlle C.A., Pereira F.M. (2019) Effects of $\mathrm{CO}_{2}$ addition on soot formation of ethylene non-premixed flames under oxygen enriched atmospheres, Combust. Flame 203, 407-423. doi: 10.1016/j.combustflame.2019.02.016.
8 Ying Y., Liu D. (2019) Effects of water addition on soot properties in ethylene inverse diffusion flames, Fuel 247, 187-197. doi: 10.1016/j.fuel.2019.03.034.

9 Engine Combustion Network (2019) [online] Available from https://ecn.sandia.gov.

10 Skeen S.A., Manin J., Pickett L.M., Cenker E., Bruneaux G., Kondo K., Aizawa T., Westlye F., Dalen K., Ivarsson A., Xuan T.A. (2016) Progress review on soot experiments and modeling in the Engine Combustion Network (ECN), $S A E$ Int. J. Engines 9, 883-898. doi: 10.4271/2016-01-0734.

11 Skeen S., Yasutomi K., Cenker E., Adamson B., Hansen N., Pickett L. (2018) Standardized optical constants for soot quantification in high-pressure sprays, SAE Int. J. Engines 11, 805-816. doi: 10.4271/2018-01-0233.

12 Westlye F.R., Penney K., Ivarsson A., Pickett L.M., Manin J., Skeen S.A. (2017) Diffuse back-illumination setup for high temporally resolved extinction imaging, Appl. Opt. 56, 5028-5038. doi: 10.1364/ao.56.005028.

13 Ghandhi J.B., Heim D.M. (2009) An optimized optical system for backlit imaging, Rev. Sci. Instrum. 80, 056105. doi: $10.1063 / 1.3128728$.

14 Manin J., Bardi M., Pickett L.M., Dahms R.N., Oefelein J.C. (2014) Microscopic investigation of the atomization and mixing processes of diesel sprays injected into high pressure and temperature environments, Fuel 134, 531-543. doi: 10.1016/j.fuel.2014.05.060.

15 Xue Q., Som S., Senecal P.K., Pomraning E. (2013) Large eddy simulation of fuel-spray under non-reacting ic engine conditions, At. Sprays 23, 925-955. doi: 10.1615/atomizspr. 2013008320.

16 Luo Z., Som S., Sarathy S.M., Plomer M., Pitz W.J., Longman D.E., Lu T. (2014) Development and validation of an n-dodecane skeletal mechanism for spray combustion applications, Combust Theory Model 18, 187-203. doi: 10.1080/13647830.2013.872807.

17 Hiroyasu H., Kadota T. (1976) Models for combustion and formation of nitric oxide and soot in direct injection diesel engines, SAE Tech. Pap. Ser., 760129. doi: 10.4271/ 760129 .

18 Wang H., Ra Y., Jia M., Reitz R.D. (2014) Development of a reduced n-dodecane-PAH mechanism and its application for n-dodecane soot predictions, Fuel 136, 25-36. doi: 10.1016/j. fuel.2014.07.028.

19 Vishwanathan G., Reitz R.D. (2010) Development of a practical soot modeling approach and its application to lowtemperature diesel combustion, Combust. Sci. Technol. 182, 1050-1082. doi: 10.1080/00102200903548124.

20 Ajrouche H., Nilaphai O., Hespel C., Foucher F. (2019) Impact of nitric oxide on n-heptane and n-dodecane autoignition in a new high-pressure and high-temperature chamber, Proc. Combust. Inst. 37 3319-3326. doi: 10.1016/j. proci.2018.07.102.

21 Ben Houidi M., Hespel C., Bardi M., Nilaphai O., Malbec L.-M., Sotton J., Bellenoue M., Strozzi C., Ajrouche H., Foucher F., Moreau B., Rousselle C., Bruneaux G. (2019) Characterization of the ECN spray A in different facilities. Part 1: boundary conditions characterization. Oil Gas Sci. Technol. - Rev. IFP Energies nouvelles. doi: 10.2516/ogst/ 2020023.

22 Payri R., Salvador F.J., Manin J., Viera A. (2016) Diesel ignition delay and lift-off length through different methodologies using a multi-hole injector, Appl. Energy 162, 541-550. doi: 10.1016/j.apenergy.2015.10.118. 
23 Lind T., Roberts G., Eagle W., Rousselle C., Andersson Ö., Musculus M.P. (2018) Mechanisms of post-injection sootreduction revealed by visible and diffused back-illumination soot extinction imaging, SAE Tech. Pap. Ser. doi: 10.4271/ 2018-01-0232.

24 Manin J., Skeen S., Pickett L., Kurtz E., Anderson J.E. (2014) Effects of oxygenated fuels on combustion and soot formation/oxidation processes, SAE Int. J. Fuels Lubr. 7, 704-717. doi: 10.4271/2014-01-2657.

25 Manin J., Pickett L.M., Skeen S.A. (2013) Two-color diffused back-illumination imaging as a diagnostic for time-resolved soot measurements in reacting sprays, SAE Int. J. Engines 6 , 1908-1921. doi: 10.4271/2013-01-2548.

26 Cenker E., Bruneaux G., Pickett L., Schulz C. (2013) Study of soot formation and oxidation in the Engine Combustion Network (ECN), spray A: Effects of ambient temperature and oxygen concentration, SAE Int. J. Engines 6, 352-365. doi: 10.4271/2013-01-0901.

27 Musculus M.P.B., Pickett L.M. (2005) Diagnostic considerations for optical laser-extinction measurements of soot in high-pressure transient combustion environments, Combust.
Flame 141, 371-391. doi: 10.1016/j.combustflame.2005. 01.013 .

28 Liu F., Guo H., Smallwood G.J., Gülder Ö.L. (2001) The chemical effects of carbon dioxide as an additive in an ethylene diffusion flame: Implications for soot and NOx formation, Combust. Flame 125, 778-787. doi: 10.1016/ S0010-2180(00)00241-8.

29 Donkerbroek A.J., Boot M.D., Luijten C.C.M., Dam N.J., ter Meulen J.J. (2011) Flame lift-off length and soot production of oxygenated fuels in relation with ignition delay in a DI heavy-duty diesel engine, Combust. Flame 158, 525-538. doi: 10.1016/j.combustflame.2010.10.003.

30 Pickett L.M., Siebers D.L. (2004) Soot in diesel fuel jets: Effects of ambient temperature, ambient density, and injection pressure, Combust Flame 138, 114-135. doi: 10.1016/J.COMBUSTFLAME.2004.04.006.

31 Lentati A.M., Chelliah H.K. (1998) Dynamics of water droplets in a counterflow field and their effect on flame extinction, Combust. Flame 115, 158-179. doi: 10.1016/ S0010-2180(97)00355-6. 